
Theoretical \& Applied Science

Candidate of Economic Sciences, associate professor of Azerbaijan State Economic University Azerbaijan Republic, Baku

p-ISSN: 2308-4944 (print) e-ISSN: 2409-0085 (online) nauka-xxi@mail.ru

Year: 2017 Issue: $11 \quad$ Volume: 55

Published: $30.11 .2017 \quad$ http://T-Science.org

SECTION 31. Economic research, finance, innovation, risk management.

\title{
THE ACTUAL ISSUES OF USING THE WORLD EXPERIENCE IN THE DEVELOPMENT OF THE NATIONAL ECONOMY IN IMPROVING THE ECONOMIC MODEL OF THE COUNTRY
}

\begin{abstract}
The topical issues of using the world experience in the development of the national economy in improving the country's economic model are explored in the article. The main mechanisms and elements of the development of the national economy, its resource availability, basic indicators and principles are analyzed. Various models and directions of development of national economy in the world are studied. The essence and main advantages, mechanisms, principles, criteria of the American, German, Japanese, Swedish, French, Chinese, South Korean, European, Islamic, and for comparing the Azerbaijani models of economic development in the modern reality are revealed. The objectivity and regularity of this or that economic model of the national economy development, proceeding from the strength of the basic mechanisms and elements of formation and activity are considered. The strategic goals and main directions of the development of the optimal model of the economic development of the national economy in the context of ensuring the country's competitiveness and security are determined.

A number of recommendations and proposals on the importance and effectiveness of using the world experience in the development of the national economy in improving the country's economic model in the face of global threats are given.

Key words: world experience, national economy, development of the national economy, economic growth, competitiveness, rationality, economic model of the country.

Language: Russian

Citation: Jafarli QA (2017) THE ACTUAL ISSUES OF USING THE WORLD EXPERIENCE IN THE DEVELOPMENT OF THE NATIONAL ECONOMY IN IMPROVING THE ECONOMIC MODEL OF THE COUNTRY. ISJ Theoretical \& Applied Science, 11 (55): 296-300.

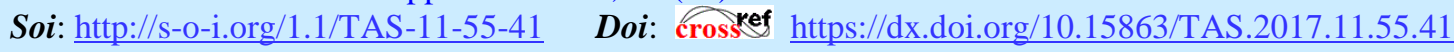

\section{АКТУАЛЬНЫЕ ВОПРОСЫ ИСПОЛЬЗОВАНИЯ МИРОВОГО ОПЫТА РАЗВИТИЯ НАЦИОНАЛЬНОЙ ЭКОНОМИКИ В СОВЕРШЕНСТВОВАНИИ ЭКОНОМИЧЕСКОЙ МОДЕЛИ} СТРАНЫ

Аннотация: В статье исследованы актуальные вопросы использования мирового опыта развития национальной экономики в совершенствовании экономической модели страны. Анализированы основные механизмы и элементы развития начиональной экономики, ее ресурсообеспеченности, основнье индикаторы и принципь. Изучены разные модели и направления развития национальной экономики в мире. Раскрыты сущчность и основные преимущества, механизмы, принщипы, критерии американской, немецкой, японской, шведской, франиузской, китайской, южно-корейской, европейской, исламской и для сопоставления азербайджанской моделей экономического развития в современной реалии. Рассмотрень объективность и закономерность той или иной экономической модели развития национальной экономики исходя от прочности основных механизмов и элементов формирования и деятельности. Определены стратегические иели и основные направления развития оптимальной модели экономического развития национальной экономики в контексте обеспечения конкурентоспособности и безопасности страны.

Дан ряд рекомендаций и предложений по важности и эффективности использования мирового опьта развития национальной экономики в совершенствовании экономической модели страны в условиях глобальных угроз.
\end{abstract}

ISPC Technological development,

Philadelphia, USA 
Ключевые слова: мировой опьт, нацииональная экономика, развитие национальной экономики, рост экономики, конкурентоспособность, рациональность, экономическая модель страны.

\section{Introduction}

Как известно, актуальные вопросы использования мирового опыта развития национальной экономики в совершенствовании экономической модели страны требуют комплексной и системной работы изучения особенности мировых экономических процессов, их эффективности, сущность и содержание отдельных экономических школ и экономических моделей, эконмическая система стран мира, рассмотрение адекватных и подходящих механизмов в развитии национальной экономики, способных противостоять глобальным угрозам и влияниям прочих негативных последствий мировых экономических и финансовых кризисов. Отметим, что в мирохозяйственной системе и мировом экономическом пространстве имеется ряд экономических моделей, которые уже зарекомендовали себя состоявших экономических моделей в продолжительности долгого периода и мировые страны последовательно рассматривают эти модели, как основу развития своих экономической системы, в целом национальной экономики. Например, американская экономическая модель в основном рассматривает принципы и механизмы либеральных рыночных отношений, углубление рыночных инфраструктуры и механизма, развитие предпринимательства на основе современных и высоких технологий. Немецкая экономическая модель больше всего основывается на усиленном государственном влиянии поддержки и развития экономических процессов, одновременно особым вниманием развитие социальной сферы. В основе японской экономической модели больше всего выделяется регулирование так называемого корпоративного капитализма с учётом соблюдения и развития принципов социального характера, повышение жизненного уровня состояния населения. В японской экономической модели особо рассматривается тесное взаимодействие “государства-частный сектор”[1].

\section{Materials and Methods}

На основе формирования прочного механизма модели экономического развития и маневрирования обеспечения устойчивого развития национальной экономики необходимо решить множественные сложные задачи и проблемы, которые зависят от эффективности применяемых практичных механизмов экономической системы страны. Все механизмы и инструментарии развития и расширения структуры, повышение конкурентоспособности национальной экономики должны базироваться на прочных и продуктивных концептуальных механизмах и задачах с определением конкретных и приоритетных направлений развития экономической модели определённой страны и обеспечением благополучия населений в целом. Одной из главных и важных индикаторов устойчивого развития национальной экономики и совершенствования модели экономического развития считается обеспечение динамики роста и повышение объёма национального продукта, услуги и прочее. Только в случае стабильности роста национальной экономики возможно комплексное рассмотрение решения стратегических задач, стоящих перед реализацией модели экономического развития страны[2]. Механизмы и основные критерии национальной экономики должны быть адекватны ресурсным потенциалам и историческим объективностям развития страны с разработкой современных эффективных практичных механизмов, стратегии, комплексных программ и долгосрочным прогнозированием основных индикаторов развития экономической системы страны. Важно, что стратегические цели национальной экономики и в целом модели экономического развития страны были основаны на конкретном ожидаемом и прогнозируемом уровне развития, который мог бы обеспечить усиление его экономической системы и благосостояния населения[3]. Кроме того, проводимая экономическая модернизация, обновление и реконструкция экономической системы страны должны настроиться одновременной на существенное повышение качественных и количественных аспектов развития национальной экономики с учётом развития человеческого фактора. В целом проводимые реформы и осуществляемая экономическая политика в стране не должна вызывать социальноэкономическое потрясение для людей, а его механизмы и практичный инструментарий должны формироваться на основе объективных и адекватных индикаторах по повышению рациональности модели экономического развития страны[4].

Следует подчеркнуть, что многие страны мира, не смотря на хватку всех видов ресурсов, в том числе наличия современных технологий не могут полноценно обеспечить устойчивость национальной экономики и избежать социальноэкономическое потрясение, от влияния негативных последствий тех или иных волн экономических и финансовых кризисов мира. Даже развитые страны на основе прочной экономической системы и экономических механизмов не смогли избежать негативные последствия последнего финансового кризиса мира и по сей день продолжается 
кропотливая работа по обеспечению роста экономики страны и повышению иммунитета его отдельных секторов. Поэтому, государства страны, отвечающие за устойчивость национальной экономики и прочность экономической системы должны глубоко изучить и систематизировать те индикаторы развития экономики страны, которые могут стать основой динамичного роста и устойчивого развития национальной экономики в современной сложной ситуации[5].Более того, требуется сбалансированность основных и главных стратегических целей развития национальной экономики с учётом повышения эффективности бизнес-среды и приоритетных сфер деятельности[6]. Справедливо исследователи Л.Куклина и С.Пономарева подчёркивают, что необходимо особо уделять внимание на практичные механизмы и инструментарии развития национальной экономики по отношению существующих традиционных механизмов страны путём их обновления и модернизации[7]. В объективности и реалии процессы развития национальной экономики страны обуславливают фундаментальной изучение отдельных направлений и сфер деятельности, которые могут быть опорным фундаментом по обеспечению устойчивости и долгосрочности стабильности экономической системы страны с учётом новых задач и проблем, порождающих исходя от глобальных экономических изменений и современных экономических вызовов. Н.Мамон отмечает, что для концептуального подхода к определению сущности национальной экономической безопасности в первую очередь необходимо разработать и подготовить концепцию по данным проблемам с учётом гарантий и защиты национальных интересов, статуса и экономического суверенитета, устойчивости национальной экономики, определения приемлемого уровня подушных доходов производства, потребления и занятости, обеспечения независимости экономической системы и эффективности производства ресурсов, гарантии предотвращения непоправимого ущерба и нейтрализации источников негативных шоков[8, c.4-5]. Все эти сложные задачи обуславливают решение множественных проблем по повышению способности модели экономического развития для обеспечения устойчивости и динамичного роста национальной экономики, расширение воспроизводства без критической зависимости от внешних факторов, обеспечение производительности и стабильности экономической системы и финансовой сферы страны. Кроме того, жёсткая конкуренция между участниками рыночных отношений обуславливает и требует оптимальный выбор институциональных элементов устойчивого роста национальной экономики[9]. Наряду с рыночными элементами и механизмами не мало важное значение имеет балансирование политических и экономических факторов формирования модели экономического развития страны[10]. Анализ показывает, что в числе особых критерий и механизмов, в то же время принципов и сущность моделей экономического развития в мире больше всего отличаются те экономические модели, которые уже имеют более устойчивые и продуктивные механизмы и конструкции, практичный инструментарий. Особенности моделей экономического развития, их механизмы, принципы и критерии более подробно даны в нижеследующей Таблице.

Таблица

Особенности, механизмы, принципы и критерии модели экономического развития мира

\begin{tabular}{|c|c|c|c|c|c|c|c|c|c|}
\hline $\begin{array}{c}\text { Америк } \\
\text { анская } \\
\text { модель }\end{array}$ & $\begin{array}{c}\text { Немецкая } \\
\text { модель }\end{array}$ & $\begin{array}{c}\text { Японская } \\
\text { модель }\end{array}$ & $\begin{array}{c}\text { Шведская } \\
\text { модель }\end{array}$ & $\begin{array}{c}\text { Французс } \\
\text { кая } \\
\text { модель }\end{array}$ & $\begin{array}{l}\text { Китайск } \\
\text { ая } \\
\text { модель }\end{array}$ & $\begin{array}{c}\text { Южно- } \\
\text { Корейска } \\
\text { я модель }\end{array}$ & $\begin{array}{c}\text { Европейс } \\
\text { кая } \\
\text { модель }\end{array}$ & $\begin{array}{c}\text { Исламск } \\
\text { ая } \\
\text { экономи } \\
\text { ческая } \\
\text { модель }\end{array}$ & $\begin{array}{c}\text { Азербайджа } \\
\text { нская } \\
\text { модель }\end{array}$ \\
\hline $\begin{array}{c}\text { государ } \\
\text { ство } \\
\text { мало } \\
\text { вмешива } \\
\text { ется в } \\
\text { экономи } \\
\text { ческие } \\
\text { процесс } \\
\text { ы }\end{array}$ & $\begin{array}{c}\text { государство } \\
\text { сильно } \\
\text { влияет на } \\
\text { экономичес } \\
\text { кие } \\
\text { процессы }\end{array}$ & $\begin{array}{c}\text { государств } \\
\text { о сильно } \\
\text { влияет на } \\
\text { экономичес } \\
\text { кие } \\
\text { процессы }\end{array}$ & $\begin{array}{c}\text { социальн } \\
\text { о- } \\
\text { ориентиро } \\
\text { ванная } \\
\text { экономич } \\
\text { еская } \\
\text { система }\end{array}$ & $\begin{array}{c}\text { государст } \\
\text { во сильно } \\
\text { влияет на } \\
\text { экономиче } \\
\text { ские } \\
\text { процессы }\end{array}$ & $\begin{array}{c}\text { смешанн } \\
\text { ая } \\
\text { модель } \\
\text { экономи } \\
\text { ческого } \\
\text { развития }\end{array}$ & $\begin{array}{c}\text { плановая } \\
\text { экономич } \\
\text { еская } \\
\text { система }\end{array}$ & $\begin{array}{c}\text { высокая } \\
\text { роль } \\
\text { государст } \\
\text { ва в } \\
\text { экономич } \\
\text { еской } \\
\text { системе }\end{array}$ & $\begin{array}{c}\text { экономи } \\
\text { ческая } \\
\text { система с } \\
\text { исламски } \\
\text { ми } \\
\text { принцип } \\
\text { ами }\end{array}$ & $\begin{array}{c}\text { социально- } \\
\text { ориентирова } \\
\text { нная } \\
\text { экономическ } \\
\text { ая система }\end{array}$ \\
\hline $\begin{array}{c}\text { сильная } \\
\text { рыночна } \\
\text { я } \\
\text { экономи } \\
\text { ка }\end{array}$ & $\begin{array}{c}\text { социально- } \\
\text { ориентиров } \\
\text { анная } \\
\text { рыночная } \\
\text { система }\end{array}$ & $\begin{array}{c}\text { подготовка } \\
\text { планов } \\
\text { экономичес } \\
\text { кого } \\
\text { развития }\end{array}$ & $\begin{array}{c}\text { государст } \\
\text { во играет } \\
\text { основную } \\
\text { роль в } \\
\text { экономич } \\
\text { еской } \\
\text { стабильно } \\
\end{array}$ & $\begin{array}{c}\text { активны } \\
\text { крупные } \\
\text { компании }\end{array}$ & $\begin{array}{c}\text { высокий } \\
\text { плановы } \\
\text { й подход } \\
\text { экономик } \\
\text { и }\end{array}$ & $\begin{array}{c}\text { высокий } \\
\text { плановы } \\
\text { й подход } \\
\text { экономик } \\
\text { и }\end{array}$ & $\begin{array}{c}\text { сильные } \\
\text { экономич } \\
\text { еские } \\
\text { законы и } \\
\text { стандарты }\end{array}$ & $\begin{array}{c}\text { механиз } \\
\text { мы и } \\
\text { принцип } \\
\text { ы на } \\
\text { исламски } \\
\text { х } \\
\text { принцип } \\
\end{array}$ & $\begin{array}{c}\text { сбалансиров } \\
\text { анная } \\
\text { экономическ } \\
\text { ая политика } \\
\text { государства }\end{array}$ \\
\hline
\end{tabular}




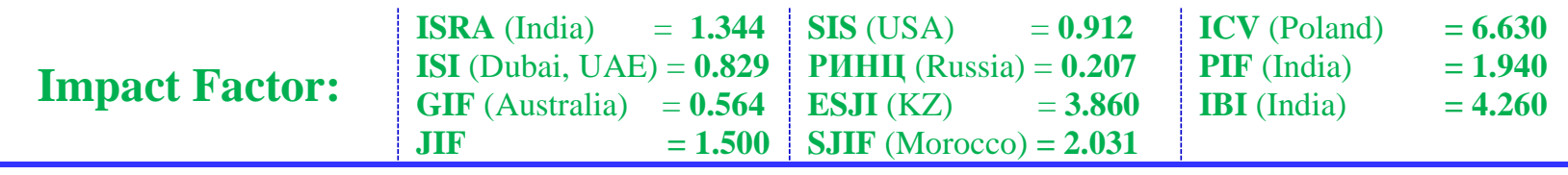

\begin{tabular}{|c|c|c|c|c|c|c|c|c|c|}
\hline & & & сти & & & & & $\mathrm{ax}$ & \\
\hline $\begin{array}{c}\text { глобали } \\
\text { зация } \\
\text { бизнеса }\end{array}$ & $\begin{array}{c}\text { спрогнозир } \\
\text { ованные } \\
\text { макроэконо } \\
\text { мические } \\
\text { показатели }\end{array}$ & $\begin{array}{c}\text { регулируем } \\
\text { ый } \\
\text { корпоратив } \\
\text { ный } \\
\text { капитализм }\end{array}$ & $\begin{array}{c}\text { государст } \\
\text { во } \\
\text { является } \\
\text { главным } \\
\text { по } \\
\text { распредел } \\
\text { ению } \\
\text { доходов }\end{array}$ & $\begin{array}{c}\text { государст } \\
\text { во активно } \\
\text { в бизнес } \\
\text { сфере }\end{array}$ & $\begin{array}{c}\text { государс } \\
\text { тво } \\
\text { активно } \\
\text { в } \\
\text { экономи } \\
\text { ческом } \\
\text { секторе }\end{array}$ & $\begin{array}{c}\text { государс } \\
\text { тво } \\
\text { полность } \\
\text { ю } \\
\text { контроли } \\
\text { рует } \\
\text { кредитну } \\
\text { ю } \\
\text { систему } \\
\end{array}$ & $\begin{array}{c}\text { высокая } \\
\text { база } \\
\text { налогообл } \\
\text { ожения }\end{array}$ & $\begin{array}{c}\text { налогова } \\
\text { я система } \\
\text { на } \\
\text { исламски } \\
\text { х } \\
\text { критерия } \\
\text { х }\end{array}$ & $\begin{array}{c}\text { активные } \\
\text { государстве } \\
\text { нные } \\
\text { экономическ } \\
\text { ие } \\
\text { инструмент } \\
\text { ы }\end{array}$ \\
\hline $\begin{array}{c}\text { активен } \\
\text { капиталь } \\
\text { ный } \\
\text { экспорт }\end{array}$ & $\begin{array}{c}\text { сильная } \\
\text { роль } \\
\text { крупных } \\
\text { компаний в } \\
\text { экономичес } \\
\text { кой системе }\end{array}$ & $\begin{array}{c}\text { высокая } \\
\text { производит } \\
\text { ельность } \\
\text { труда }\end{array}$ & $\begin{array}{c}\text { высокая } \\
\text { база } \\
\text { налогообл } \\
\text { ожения }\end{array}$ & $\begin{array}{c}\text { высокийп } \\
\text { лановый } \\
\text { подход } \\
\text { экономики }\end{array}$ & $\begin{array}{c}\text { активны } \\
\text { е } \\
\text { экономи } \\
\text { ческие } \\
\text { инструме } \\
\text { нты }\end{array}$ & $\begin{array}{c}\text { государс } \\
\text { тво } \\
\text { полность } \\
\text { ю } \\
\text { контроли } \\
\text { рует } \\
\text { финансов } \\
\text { ую } \\
\text { систему }\end{array}$ & $\begin{array}{c}\text { высокая } \\
\text { финансов } \\
\text { ая } \\
\text { обеспечен } \\
\text { ность } \\
\text { сектора } \\
\text { образован } \\
\text { ия и } \\
\text { культуры }\end{array}$ & $\begin{array}{c}\text { кредитн } \\
\text { ый } \\
\text { механиз } \\
\text { м на } \\
\text { исламски } \\
\text { х } \\
\text { принцип } \\
\text { ах }\end{array}$ & $\begin{array}{c}\text { развитые } \\
\text { бизнес-среда } \\
\text { и } \\
\text { предприним } \\
\text { ательства }\end{array}$ \\
\hline $\begin{array}{c}\text { мобиль } \\
\text { ная } \\
\text { система } \\
\text { управле } \\
\text { ния }\end{array}$ & $\begin{array}{c}\text { сильная } \\
\text { социальная } \\
\text { инфраструк } \\
\text { тура }\end{array}$ & $\begin{array}{c}\text { высокий } \\
\text { уровень } \\
\text { планирован } \\
\text { ия }\end{array}$ & $\begin{array}{c}\text { безработи } \\
\text { ца на } \\
\text { уровне } \\
\text { минимума }\end{array}$ & $\begin{array}{c}\text { государст } \\
\text { во активно } \\
\text { вмешивает } \\
\text { ся в } \\
\text { движение } \\
\text { капитала }\end{array}$ & $\begin{array}{c}\text { высокий } \\
\text { экспортн } \\
\text { ый } \\
\text { потенциа } \\
\text { л }\end{array}$ & $\begin{array}{c}\text { высокий } \\
\text { экспортн } \\
\text { ый } \\
\text { потенциа } \\
\text { л }\end{array}$ & $\begin{array}{c}\text { государст } \\
\text { во } \\
\text { занимает } \\
\text { основное } \\
\text { место в } \\
\text { сет } \\
\text { инфрастр } \\
\text { уктуры }\end{array}$ & $\begin{array}{c}\text { програм } \\
\text { мы } \\
\text { экономи } \\
\text { ческого } \\
\text { развития } \\
\text { на } \\
\text { исламски } \\
\text { х } \\
\text { критерия } \\
\text { х }\end{array}$ & $\begin{array}{c}\text { имеются } \\
\text { стратегическ } \\
\text { ие } \\
\text { экономическ } \\
\text { ие цели } \\
\text { развития }\end{array}$ \\
\hline $\begin{array}{c}\text { высокий } \\
\text { экспорт } \\
\text { ный } \\
\text { потенци } \\
\text { ал }\end{array}$ & $\begin{array}{c}\text { сильные } \\
\text { рыночные } \\
\text { механизмы }\end{array}$ & $\begin{array}{c}\text { сотрудниче } \\
\text { ство } \\
\text { государства } \\
\text { и частного } \\
\text { сектора }\end{array}$ & $\begin{array}{l}\text { потенциа } \\
\text { л } \\
\text { экспорта } \\
\text { высокий }\end{array}$ & $\begin{array}{c}\text { потенциа } \\
\text { л экспорта } \\
\text { высокий }\end{array}$ & $\begin{array}{l}\text { достаточ } \\
\text { ные } \\
\text { трудовые } \\
\text { ресурсы }\end{array}$ & $\begin{array}{c}\text { высокое } \\
\text { стимулир } \\
\text { ование } \\
\text { экспорта }\end{array}$ & $\begin{array}{c}\text { имеются } \\
\text { программ } \\
\text { ы } \\
\text { националь } \\
\text { ной } \\
\text { развития } \\
\end{array}$ & $\begin{array}{c}\text { достаточ } \\
\text { ные } \\
\text { трудовые } \\
\text { ресурсы }\end{array}$ & $\begin{array}{c}\text { высокое } \\
\text { стимулирова } \\
\text { ние экспорта }\end{array}$ \\
\hline $\begin{array}{c}\text { высокий } \\
\text { уровень } \\
\text { жизни и } \\
\text { т.д. }\end{array}$ & $\begin{array}{c}\text { справедлив } \\
\text { ая } \\
\text { социальная } \\
\text { среда и т.д. }\end{array}$ & $\begin{array}{c}\text { социально- } \\
\text { ориентиров } \\
\text { анная } \\
\text { модель и } \\
\text { т.д. }\end{array}$ & $\begin{array}{c}\text { высокий } \\
\text { уровень } \\
\text { жизни } \\
\text { населения } \\
\text { и т.д. }\end{array}$ & $\begin{array}{c}\text { высокий } \\
\text { уровень } \\
\text { жизни и } \\
\text { т.д. }\end{array}$ & $\begin{array}{c}\text { развивае } \\
\text { тся } \\
\text { уровень } \\
\text { жизни и } \\
\text { т.д. }\end{array}$ & $\begin{array}{c}\text { политик } \\
\text { а } \\
\text { ограниче } \\
\text { нного } \\
\text { импорта } \\
\text { и т.д. }\end{array}$ & $\begin{array}{c}\text { справедл } \\
\text { ивая } \\
\text { социальна } \\
\text { я } \\
\text { политика, } \\
\text { высокий } \\
\text { уровень } \\
\text { жизни и } \\
\text { т.д. }\end{array}$ & $\begin{array}{c}\text { исламск } \\
\text { ие } \\
\text { ценности } \\
, \\
\text { традиции } \\
, \\
\text { социальн } \\
\text { ая } \\
\text { политика } \\
\text { и т.д. }\end{array}$ & $\begin{array}{c}\text { проводится } \\
\text { справедлива } \\
\text { я } \\
\text { социальная } \\
\text { политика и } \\
\text { т.д. }\end{array}$ \\
\hline
\end{tabular}

\section{Conclusion}

Таким образом, в числе основных моделей развития и устойчивости национальной экономики больше всего отличаются те страны, которые в современном мире возглавляют центр экономической мощности и основных финансовых ресурсов. Более того, в настоящее время идёт ожесточённая конкуренция за преобладания моделей экономического развития противоположных континентов, например, верховенство и господство на мировом рынке и в мировой экономике между США и Китаем с каждым годом меняется в пользу последнего. Кроме того, между европейской моделями экономического развития с аналогичными моделями азиатского региона происходит то же самое, т.е. азиатские модели развития экономики набирают более динамичные обороты развития, чем другие модели экономического развития. Успех той или иной экономической модели в ближайшей перспективе больше всего будет зависеть от прочности основных механизмов и конструкций моделиэкономического развития, её маневренности, гибкости, оптимальной и сбалансированной ресурсообеспеченности, роста населения и трудовых ресурсов, и одновременно умелого и рационального государственного экономической политик по обеспечению устойчивости и конкурентоспособности национальной экономики в условиях глобальных угроз и постоянно меняющихся мирохозяйственных систем, мировых экономических процессов и т.д. 


\begin{tabular}{l|lrl|l|ll} 
& ISRA (India) & $=\mathbf{1 . 3 4 4}$ & SIS (USA) & $=\mathbf{0 . 9 1 2}$ & ICV (Poland) & $=\mathbf{6 . 6 3 0}$ \\
Impact Factor: & ISI (Dubai, UAE) $=\mathbf{0 . 8 2 9}$ & PUHL (Russia) $=\mathbf{0 . 2 0 7}$ & PIF (India) & $=\mathbf{1 . 9 4 0}$ \\
& GIF (Australia) & $\mathbf{0 . 5 6 4}$ & ESJI (KZ) & $=\mathbf{3 . 8 6 0}$ & IBI (India) & $=\mathbf{4 . 2 6 0}$ \\
& JIF & $\mathbf{1 . 5 0 0}$ & SJIF (Morocco) & $=\mathbf{2 . 0 3 1}$ & & \\
\hline
\end{tabular}

\section{References:}

1. Fukunari Kimura (2017) Japan's Model of Economic Development. Relevant and Nonrelevant Elements for Developing Economics. KenioUniversity, Tokyo. Available: http://www.citeseerx.ist.psu.edu. (Accessed: 10.11.2017).

2. Solow R.M. (1970) Growth Theory: An Exposition. Oxford.

3. ChalletD., Marsili M., ZhangY.C. (2005) Minority Games. Oxford University Press: Oxford.

4. Kahneman D., Tversky A. (2000) Choices, Values, and Frames. Cambridge University Press, Cambridge.
5. (2003) The Efficient Market Hypothesis and Its Critics by Burton G. Malkiel, Princeton University CEPS Working Paper No. 91, 2003.

6. Fama E. (1970) Efficient Capital Markets: A Review of Theory and Empirical Work. Journal of Finance 25 (2): 1970. -p. 383-417.

7. Kuklina L.N., Ponomareva S.I. (2012) Novaya makroekonomicheskaya model' natsional'noy ekonomiki//Ekonomika regiona, №1.

8. Mamon N.V. (2017) Natsional'naya ekonomicheskaya bezopasnost': sushchnost' i iyerarkhicheskaya struktura.

9. Alber Michel (1993) Capitalism Against Capitalism. London: Whurr.

10. Müller-Armack Alfred (1947) The regulation of the economy and the market economy. 